space is narrow, can bleed and the blood dissect into the cerebral parenchyma without a scar formed by a previous rupture.

The history of previous bleeding is, therefore, considered to be an important factor in recognizing a localized space-expanding hematoma in cases of ruptured intracranial aneurysm. In addition, certain locations of the aneurysm as seen angiographically may also be suggestive in suspecting this potentially treatable complication.

\title{
70. Retinal Hemorrhage Caused by Subarachnoid Hemorrhage
}

Akira Kinoshita, Shinobu Igarashi, Minoru Hayashi and Sinjiro Yamamoto

Department of Neurosurgery, University_of Kanagawa

\section{Problems in Hypothermic}

Anesthesia for Direct Surgical Treatment of Intracranial Aneurysms, with Special Reference to Ventricular Fibrillation

\author{
Ryungchan Kwak, Yoshinobu Okudaira, \\ Shinrou Komatsu and Jiro Suzuki \\ Division of Neurosurgery, Institute of Brain Diseases, \\ Tohoku University School of Medicine, Sendai
}

The direct surgical treatment of intracranial aneurysms was performed in 274 cases in our institute from 1942 up to the end of 1969.

Mortality rate during hospitalization was 8.8 per cent. Hypothermic anesthesia seemed to be one of the factors attributed to this low rate of mortality. On the other hand, ventricular fibrillation was the most serious complication in hypothermic anesthesia.

Problems in hypothermic anesthesia for direct surgical treatment of intracranial aneurysms were discussed, with special reference to ventricular fibrillation.

1) Direct surgical treatments were performed in 251 cases among 254 cases of intracranial aneurysms under hypothermic anesthesia in 259 times. In three cases the operation had to be cancelled due to the occurence of ventricular fibrillation.

2) During hypothermia ether was used in 95 per cent, while fluothane in 3.0 
per cent and penthrane in 1.7 per cent.

3) Moderate hypothermic anesthesia was performed in almost all cases (90 per cent), with the lowest body temperature ranging between $25-29^{\circ} \mathrm{C}$.

4) Complications occurred in 61 cases ( 24 per cent), but most of them were transient arrhythmias and did not affect the postoperative course except ventricular fibrillation.

5) Ventricular fibrillation occurred in 6 cases (2.4 per cent). Five cases were successfully resuscitated, three cases of which were operated uneventfully, but two cases had to be cancelled in performing surgery and one case could not be resuscitated.

6) The possible causes of ventricular fibrillation in these cases were thought to be postural changes, especially an abrupt change of the head and neck position, decrease in effective circulatory blood volume due to mannitol transfusion added for preoperative dehydration, hypersensitivity of the heart muscle to cathecholamine due to hyperpotassemia under fluothane anesthesia as well as ventricular hypertrophy or myocardial damage.

\title{
72. Cerebral Metabolism Following Severe Head Injury
}

\section{-Special Reference to Arterio-Jugular Venous Oxygen Difference-}

\author{
Takao Minami, M. D., Kikushi Katsurada, M. D., \\ Ryohei Yamada, M. D., Ichiro Tahara, M. D. \\ and Tsuyoshi Sugrmoto, M. D. \\ Department of Traumatology, Osaka University Medical School
}

To investigate the cerebral metabolism following head injury, thirty-three patients were studied. All the patients were suffering from recent severe head injury and were unconscious; 8 of them were semicomatose, 8 comatose and remaining 17 in the state of brain death. Blood samples were taken from the internal jugular venous bulb by percutaneous puncture, and compared with arterial and mixed venous blood samples which were obtained simultaneously.

Narrowed arterio-jugular venous difference of oxygen content $\left(\mathrm{Ca}-\mathrm{JvO}_{2}\right)$ was of common finding in all cases, and the value was paralleled to the extent of cerebral injury. Whole cases of brain death showed extreme narrowing of $\mathrm{Ca}-\mathrm{jvO} \mathrm{O}_{2}$ of below $3 \mathrm{vol} \%$. Low $\mathrm{Ca}-\mathrm{jvO} \mathrm{O}_{2}$ value was also paralleled to the decrease of arterial oxygen content $\left(\mathrm{CaO}_{2}\right)$ and $\mathrm{Hb}$ content. Lowered arterial $\mathrm{CO}_{2}$ partial pressure $\left(\mathrm{PaCO}_{2}\right)$ by hyperventilation widened $\mathrm{Ca}-\mathrm{jv} \mathrm{O}_{2}$ values, but this $\mathrm{CO}_{2}$ response was minimum in deeply comatose patients and not observed in the state of brain death at all.

$\mathrm{PO}_{2}$ values of mixed venous blood were higher than those of internal jugular venous blood in the semicomatose and comatose patients, but inverse relation were 